\title{
Dispersive Liquid-Liquid Microextraction Based on Solidification of Floating Organic Drop Followed by Gas Chromatography-Electron Capture Detector for Determination of Some Pesticides in Water Samples
}

\author{
Mostafa Bashiri Juybari, ${ }^{1}$ Ali Mehdinia, ${ }^{2}$ Ali Jabbari, ${ }^{1}$ and Yadollah Yamini ${ }^{3}$ \\ ${ }^{1}$ Department of Chemistry, Faculty of Sciences, K.N. Toosi University of Technology, Tehran 1969764499, Iran \\ ${ }^{2}$ Department of Marine Living Resources, Iranian National Institute for Oceanography, Tehran 1411813389, Iran \\ ${ }^{3}$ Department of Chemistry, Tarbiat Modares University, P.O. Box 14115-175, Tehran, Iran
}

Correspondence should be addressed to Ali Mehdinia, mehdi_3848@yahoo.com

Received 21 June 2011; Revised 24 August 2011; Accepted 5 September 2011

Academic Editor: Kanji Miyabe

Copyright (C) 2011 Mostafa Bashiri Juybari et al. This is an open access article distributed under the Creative Commons Attribution License, which permits unrestricted use, distribution, and reproduction in any medium, provided the original work is properly cited.

\begin{abstract}
In this study dispersive liquid-liquid microextraction based on solidification of floating organic drop (DLLME-SFO) followed by gas chromatography-electron capture detection (GC-ECD) was developed for determination of some pesticides in the water samples. Some important parameters, such as type and volumes of extraction and disperser solvent and salt effect on the extraction recovery of analytes from aqueous solution were investigated. Under the optimum conditions (extraction solvent: 1-undecanol, $15.0 \mu \mathrm{L}$; disperser solvent: acetone, $1.0 \mathrm{~mL}$, and without salt addition), the preconcentration factors were obtained ranged from 802 to 915 for analytes. The linear ranges were from 0.05 to $100 \mu \mathrm{g} \mathrm{L}^{-1}$, and detection limits ranged from 0.05 to $0.008 \mu \mathrm{g} \mathrm{L}-1$. The relative standard deviations (RSDs $\%, n=5$ ) were between $3.2 \%$ and $6.7 \%$. The proposed method was successfully applied to the determination of target analytes in the tap, sea, and river water samples, and satisfactory recoveries were obtained.
\end{abstract}

\section{Introduction}

Nowadays, pesticides are one of the most prevalent environmental pollutants. Detection of pesticides and their metabolites in environmental water is an important task, especially for ground water that is used for drinking purposes. Butachlor [2-chloro- $N$-(2,6-diethylphenyl)$N$-(butoxymethyl) acetanilide] is an amber liquid with melting point $0.5-1.5^{\circ} \mathrm{C}$, boiling point $156^{\circ} \mathrm{C}$, decomposing point $165^{\circ} \mathrm{C}$, saturated vapor pressure $\left(25^{\circ} \mathrm{C}\right) 6.0 \times 10^{-4} \mathrm{~Pa}$, and water solubility $\left(20^{\circ} \mathrm{C}\right) 20 \mathrm{mg} \mathrm{L}^{-1}$. It is a recently registered preemergence herbicide belonging to the chloroacetanilide family and it is widely used to control grasses in rice crops. Despite the high rates of butachlor application, there is little information available about the occurrence of this herbicide in the environment. Butachlor has a moderate persistence in soil, but persists for a long time in water [1]. Other findings suggest that butachlor is a suspected carcinogen able to stimulate cell proliferation and induce malignant transformation in vitro [2]. Dichlorvos (DDVP), as an organophosphorous insecticide, is used widely for crop protection mainly in greenhouses and for controlling parasites and insects in houses, aircraft, and outdoor areas (as aerosols, liquid sprays) [3]. LD50 of DDVP for mouse $87 \mathrm{mg} \mathrm{kg}^{-1}$, rabbit $205 \mathrm{mg} \mathrm{kg}^{-1}$, and man $400 \mathrm{mg} \mathrm{kg}^{-1}[3,4]$. Consequently, it becomes necessary to remove the residues of this toxic compound from matrices such as water by devising an efficient and economic purification method.

Endosulfan (6,7,8,9,10,10-Hexachloro-1,5,5a,6,9,9a-hexahydro-6,9-methano-2,4,3-benzo dioxathiepine-3-oxide) is an off-patent organochlorine insecticide and acaricide that is being phased out globally. Endosulfan became a highly controversial agrichemical due to its acute toxicity, potential for bioaccumulation, and role as an endocrine disruptor. Because of its threats to human health and the environment, 
a global ban on the manufacture and use of endosulfan was negotiated under the Stockholm Convention in April 2011. The ban will take effect in mid-2012, with certain uses exempted for 5 additional years. More than 80 countries, including the European Union, Australia, and New Zealand, several West African nations, the United States, Brazil, and Canada had already banned it or announced phase outs by the time the Stockholm Convention ban was agreed upon. It is still used extensively in India, China, and few other countries. It is produced by Makhteshim Agan and several manufacturers in India and China. Endosulfan is acutely neurotoxic to both insects and mammals, including humans. The US EPA classifies it as Category I: "highly acutely toxic" based on a $\mathrm{LD}_{50}$ value of $30 \mathrm{mg} \mathrm{kg}^{-1}$ for female rats, while the World Health Organization classifies it as Class II "moderately hazardous" based on a rat $\mathrm{LD}_{50}$ of $80 \mathrm{mg} \mathrm{kg}^{-1}$. Doses as low as $35 \mathrm{mg} \mathrm{kg}^{-1}$ have been documented to cause death in humans. Endosulfan can promote proliferation of human breast cancer cells [5].

Sample preparation prior to chromatographic analysis is one of the most critical steps in analytical processes. A number of traditional methods have been proposed for the isolation, extraction, and concentration of pesticides from various matrices, including liquid-liquid extraction (LLE) [6] and solid-phase extraction (SPE) [7]. They are time consuming, labor-intensive, and tedious methods. Moreover, LLE requires a large amount of toxic and environmentally unfriendly organic solvent. In the past decades, miniaturization and development of environmental friendly methods have become the trend in analytical chemistry. Many microextraction techniques have been developed. Solidphase microextraction (SPME), a solvent-free technique, was developed by Arthur et al. [8] and is used in various analyses [9-11]. But in this technique, the fibers are expensive and some of them are fragile. The problem of samples carry-over sometimes cannot be eliminated [12].

Then liquid-phase microextraction (LPME) was introduced by Jeannot and Cantwell in 1996 [13]. Since it minimized solvent usage and solvent-variation, LPME was interesting to many analysts. Single drop microextraction (SDME) [14, 15], solvent bar microextraction (SBME) [16, 17], hollow-fiber LPME (HF-LPME) [18-20], and liquid-liquid-liquid microextraction (LLLME) [21-23] have been developed during the past few years. However, long extraction time was required to obtain good extraction efficiencies. To overcome this disadvantage, dispersive liquidliquid microextraction (DLLME) was introduced by Rezaee et al. in 2006 [24]. In this method, an appropriate mixture of extraction solvent and disperser solvent are used. The surface areas between extraction solvent and sample solution are infinitely large initially because a cloudy solution can be formed. Therefore, the extraction equilibrium can reach quickly. The method has attracted much attention due to its advantages such as fast analysis, low consumption of organic solvent, and simplicity $[25,26]$. However, the extract solvent is limited in the solvents which have higher density than water, such as chlorobenzene, chloroform, carbon tetrachloride, and carbon disulfide, and all of them are toxic and environment-unfriendly.
Recently, a new mode of liquid-phase microextraction based on solidification of floating organic droplet (LPMESFO) was developed $[27,28]$. In this method, no specific holders such as the needle tip of microsyringe, the hollow fiber, and polychloroprene rubber (PCR) tube is required for supporting the organic microdrop due to the using of organic solvent with low density and proper melting point. Furthermore, the extractant droplet can be collected easily by solidifying it in the lower temperature. However, the extraction time was somewhat long, thus it cannot satisfy the demand of fast analysis. A novel dispersive liquid-liquid microextraction method based on solidification of floating organic drop (DLLME-SFO) was introduced by Leong and Huang [29]. It is based on DLLME and solidification of floating organic drop [24, 27]. Despite many benefits of DLLME, the choice of the extraction solvent is its main drawback. In DLLME, solvents with the densities higher than water are required, and it used extraction solvent with higher toxicity instead of solvent with low toxic in DLLME-SFO. Furthermore, it overcomes the most important problem in DLLME that small extraction efficiency is obtained for determination of mentioned pesticides in water samples. DLLME-SFO was developed for the determination of halogenated organic compounds (HOCs) and polycyclic aromatic hydrocarbons (PAHs) in water samples [30, 31]. This technique is easily carried out. The large contact surface between the sample and the droplets of extractants speeds up mass transfer, as fast as DLLME and shorter extraction time than liquid-liquid microextraction based on solidification of floating organic droplet (LLME-SFO). In this method, there is no need to use conical bottom glass tubes, which are easily damaged and hard to clean. The floated extractant is solidified and is easily collected for analysis.

In the present study, DLLME-SFO was developed for the extraction and determination of some pesticides from aqueous samples, and a series of parameters influencing the extraction recovery were investigated systematically.

\section{Experimental}

2.1. Reagents and Standards. Three pesticides, namely, endosulfan (ENDUS) (99.9\%), butachlor (BUTA) (99.1\%), and dichlorvos (DDVP) $(99.7 \%)$ were purchased from Chem Service (West Chester, Pa, USA). All solvents and materials were obtained from Merck (Darmstadt, Germany). Doubledistilled water was used for the preparation of aqueous solution. The water used was purified on a Youngling ultrapure water purification system (Aqua Max-ultra, Republic of Korea).

Each of the pesticides $(0.010 \mathrm{~g})$ was dissolved in $5.0 \mathrm{~mL}$ methanol to obtain standard solutions with a concentration of $2000 \mathrm{mg} \mathrm{L}^{-1}$. Stock standard mixture of $10 \mathrm{mg} \mathrm{L}^{-1}$ of target solutions was prepared in methanol by dilution of standard stock solutions. A fresh $10 \mathrm{mg} \mathrm{L}^{-1}$ standard mixture containing pesticides was prepared in methanol every week and stored at $4^{\circ} \mathrm{C}$. Tap, sea, and river water samples, used for the evaluation of the method, were collected in glass bottles from the tap (Tehran, Iran), Caspian Sea (Sari, Iran), 


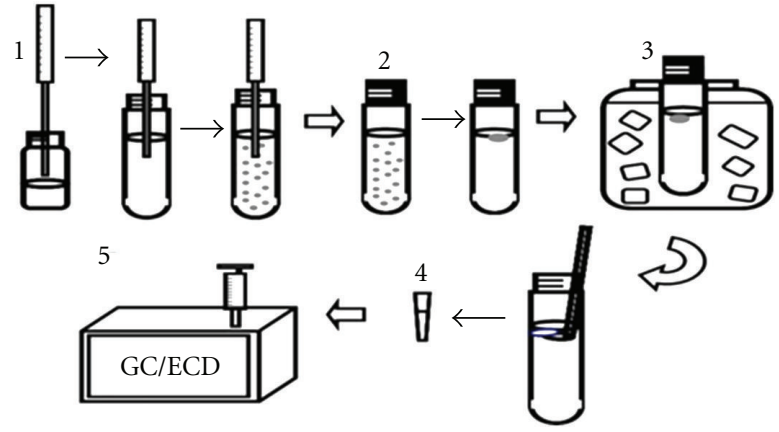

FIGURE 1: Schematic diagram of the proposed DLLME-SFO apparatus.

and Syahrood (Juybar, Iran), respectively, and stored at $4^{\circ} \mathrm{C}$. The water samples were filtered through a $0.45 \mu \mathrm{m}$ Millipore cellulose acetate syringe filter (Milford, Mass, USA).

2.2. Instrumentation. Separation, identification, and quantification were carried out on a Chrompack CP-9000 (Chrompack, Middleburg, The Netherlands) gas chromatography system equipped with an electron capture detector. Nitrogen (with $99.999 \%$ purity) was used as carrier (flow rate $=0.5 \mathrm{~mL} \mathrm{~min}{ }^{-1}$ ). The inlet was operated in the split mode with a split ratio of $1: 10$. Separation of pesticides was carried out using a Chrompack CP-Sil $8 \mathrm{CB}$ fused-silica capillary column (Chrompack, Middleburg, The Netherlands) specialized for pesticides separation $(30 \mathrm{~m} \times$ 0.32 I.D., $0.25 \mu \mathrm{m}$ film thickness). The injector and detector temperatures were set at $250^{\circ} \mathrm{C}$ and $280^{\circ} \mathrm{C}$, respectively. The GC oven was kept at $70^{\circ} \mathrm{C}$ for 5 min then raised to $200^{\circ} \mathrm{C}$

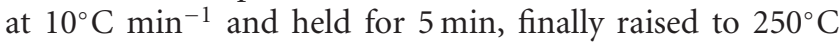

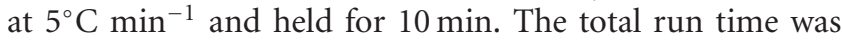
$40 \mathrm{~min}$. All chromatograms were recorded and processed by the Maestro software, version 2.4.

2.3. DLLME-SFO Procedure. A diagrammatic sketch of DLLME-SFO is shown in Figure 1. (1) An aqueous sample $(5 \mathrm{~mL})$ of water free from pesticides was placed in a $10 \mathrm{~mL}$ screw cap glass test tube, and $50 \mu \mathrm{L}$ of stock solution ( $10 \mathrm{mg} \mathrm{L}^{-1}$ ) was spiked. $1 \mathrm{~mL}$ of acetone containing $15 \mu \mathrm{L}$ of 1 -undecanol was rapidly injected into the sample solution with a Hamilton $1 \mathrm{~mL}$ syringe (Reno, Nev, USA). (2) A cloudy solution, resulting from the dispersion of fine 1undecanol droplets in the aqueous solution, was formed in the test tube. (3) After centrifugation for $10 \mathrm{~min}$ at $6000 \mathrm{rpm}$, the glass tube was transferred into a breaker containing crushed ice; the organic solvent was solidified in $5 \mathrm{~min}$. (4) After $5 \mathrm{~min}$, the solidified solvent was transferred to a conical vial; it melted quickly at room temperature and $2 \mu \mathrm{L}$ (for GC/ECD) of the extractant was injected into the gas chromatograph for analysis.

\section{Results and Discussion}

In order to optimize DLLME-SFO for the determination of pesticides in water samples, the effects of different parameters were investigated. These conditions included type and volume of extraction and disperser solvents and ionic strength of the solutions. Finally, these selected conditions were utilized to extract pesticides in the water samples. Preconcentration factor (PF) was calculated based on the following equations

$$
\mathrm{PF}=\frac{C_{\text {floating }}}{C_{0}},
$$

where, $\mathrm{PF}, C_{\text {floating }}$, and $C_{0}$ are the preconcentration factor, concentration of the analyte in the floating organic drop, and initial concentration of the analyte in the aqueous sample. $C_{\text {floating }}$ is calculated from a calibration curve which was obtained by direct injection of analytes with the concentration ranges of $10-1000 \mathrm{mg} \mathrm{L}^{-1}$.

3.1. Optimization of Extraction Parameters. Before the analysis, preliminary studies were performed to investigate the interaction between variables affecting the analyte responses and no significant interaction between variables on the analyte responses was observed. Therefore, optimization of the extraction SPME conditions was carried out using "onevariable-at-a-time" procedure.

3.2. Effect of Type and Volume of the Extraction Solvent. Selecting a suitable extraction solvent is crucial in this method. In DLLME method, extraction solvent should have low solubility in water, high affinity to analytes, lower density than water, and good chromatographic behavior. In this work, some organic solvents were selected as extraction solvent, including 1-undecanol, chloroform, chlorobenzene, carbon disulfide, and carbon tetrachloride, and their extraction efficiency were studied. Experiments were performed using different volume of these solvents to obtain about $5 \mu \mathrm{L}$ volume of sedimented phase. For this reason, $1 \mathrm{~mL}$ of acetone containing $12,25.6,13$, and $45 \mu \mathrm{L}$ of $\mathrm{C}_{6} \mathrm{H}_{5} \mathrm{Cl}, \mathrm{CS}_{2}, \mathrm{CCl}_{4}$, and $\mathrm{CHCl}_{3}$ were used, respectively. The results are shown in Figure 2. As can be seen in this figure, the extraction efficiencies using DLLME solvents are not desirable values. Further, DLLME-SFO was used for extraction of these pesticides. For DLLME-SFO, $1 \mathrm{~mL}$ acetone containing $15 \mu \mathrm{L}$ 1 -undecanol was used to achieve about $5 \mu \mathrm{L}$ volume of sedimented phase. 1-undecanol was selected as extraction solvent, due to the highest peak area obtained in comparison with other solvents as shown in Figure 2. The effect of the 1-undecanol volume on the extraction efficiency was also investigated. Experiments were performed with different volumes of 1 -undecanol $(15,20,25,30,35$, and $40 \mu \mathrm{L})$ as the extraction solvent and the volume of acetone was $1 \mathrm{~mL}$. As shown in Figure 3, the PF decrease with increasing the volume of 1-undecanol, because of increasing the volume of sedimented phase. Hence, $15 \mu \mathrm{L}$ of 1 -undecanol was selected as the optimal volume of extraction solvent to obtain higher PF.

3.3. Effect of Type and Volume of Disperser Solvent. Disperser solvent must be miscible with the extraction solvent and the aqueous sample. For these purposes, acetone, acetonitrile, 


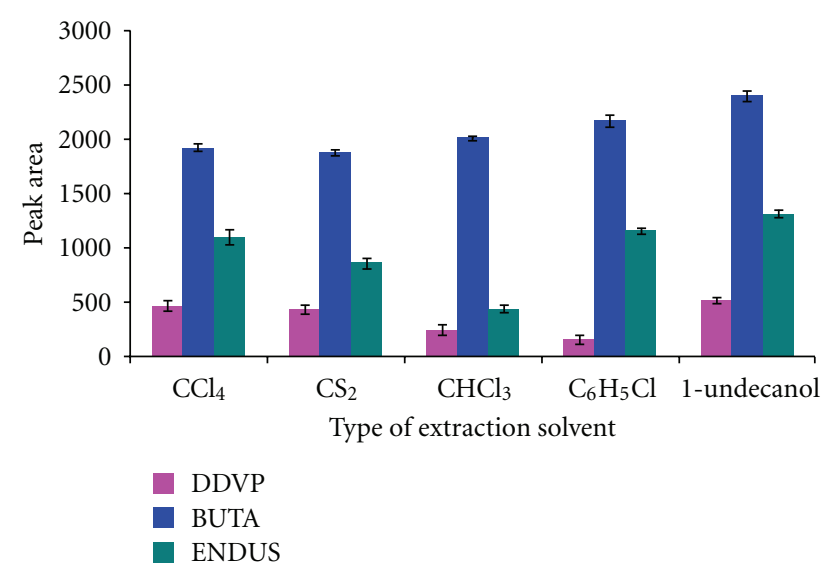

Figure 2: The effect of type of extraction solvent on the peak areas of analytes. Extraction conditions: water sample volume, $5.0 \mathrm{~mL}$; disperser solvent (acetone) volume, $1.0 \mathrm{~mL}$; extraction solvent volumes, $45.0 \mu \mathrm{L} \mathrm{CHCl}_{3}, 12.0 \mu \mathrm{L} \mathrm{C}_{6} \mathrm{H}_{5} \mathrm{Cl}, 13.0 \mu \mathrm{L} \mathrm{CCl}_{4}, 25.6 \mu \mathrm{L} \mathrm{CS}_{2}$, and $15 \mu \mathrm{L}$ 1-undecanol; concentration of analytes, $100 \mu \mathrm{g} \mathrm{L}^{-1}$.

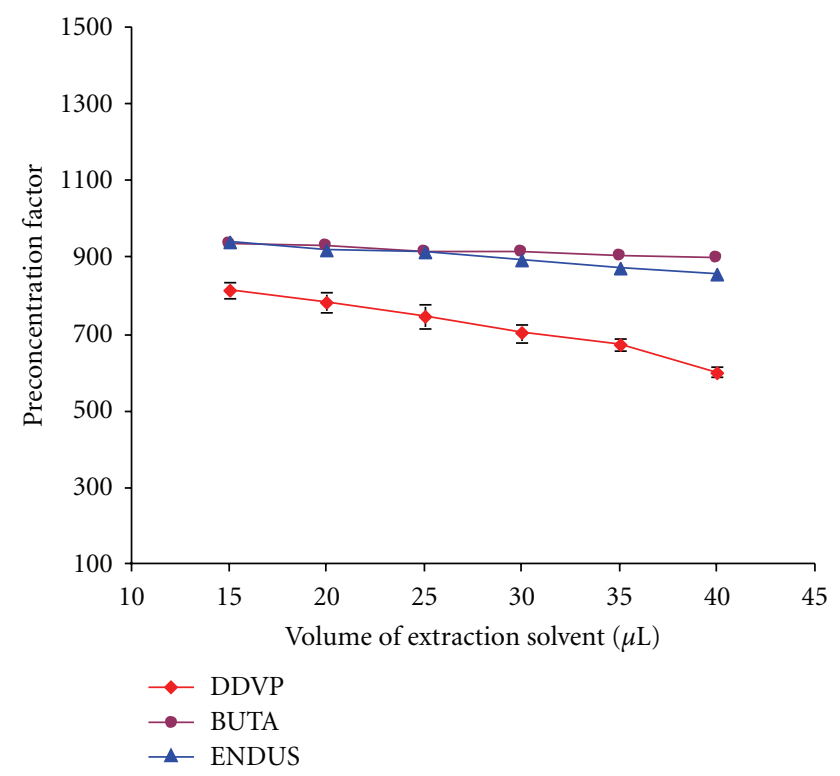

FIGURE 3: The effect of extraction solvent (1-undecanol) volume on the preconcentration factor of analytes. Extraction conditions: water sample volume, $5.0 \mathrm{~mL}$; disperser solvent (acetone) volume, $1.0 \mathrm{~mL}$; extraction solvent (1-undecanol) volumes, 15.0, 20.0, 25.0, 30.0 , 35, and $40 \mu \mathrm{L}$; concentration of analytes, $100 \mu \mathrm{g} \mathrm{L}^{-1}$.

and methanol were tested. A series of sample solutions were studied by using $1 \mathrm{~mL}$ of each disperser solvent containing $15 \mu \mathrm{L}$ extraction solvent to achieve $5 \mu \mathrm{L}$ of volume of sedimented phase. The results are shown in Figure 4. Acetone was selected because of its highest peak area than other solvents, lower toxicity, and lower price in compared to methanol and acetonitrile. For investigating the effect of volume of disperser solvent on peak areas, various volumes of acetone $0.5,1,1.5$, and $2 \mathrm{~mL}$ containing $9,15,25$, and $30 \mu \mathrm{L}$ of 1 -undecanol were tested to obtain constant volume

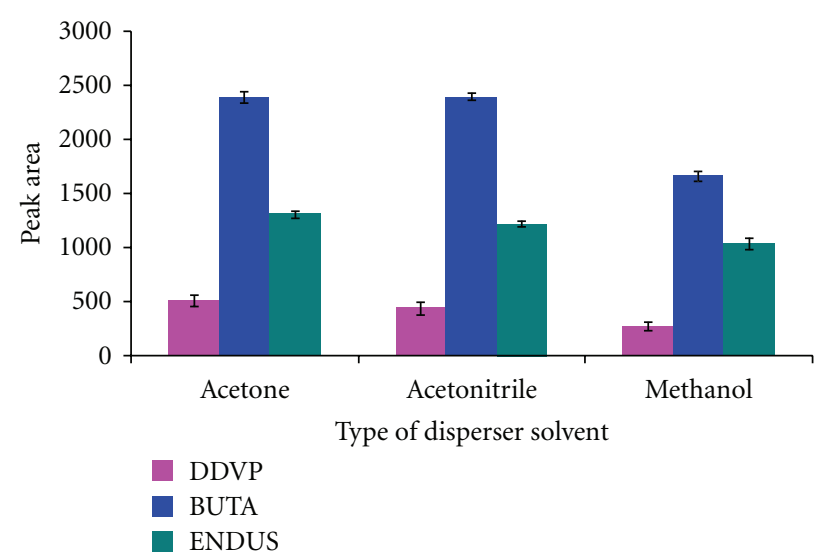

FIGURE 4: The effect of type of disperser solvent on the peak areas of analytes. Extraction conditions: water sample volume, $5.0 \mathrm{~mL}$; disperser solvent, acetone, acetonitrile, and methanol volume, $1.0 \mathrm{~mL}$; extraction solvent volumes, $15 \mu \mathrm{L}$ 1-undecanol; concentration of analytes, $100 \mu \mathrm{g} \mathrm{L}{ }^{-1}$.

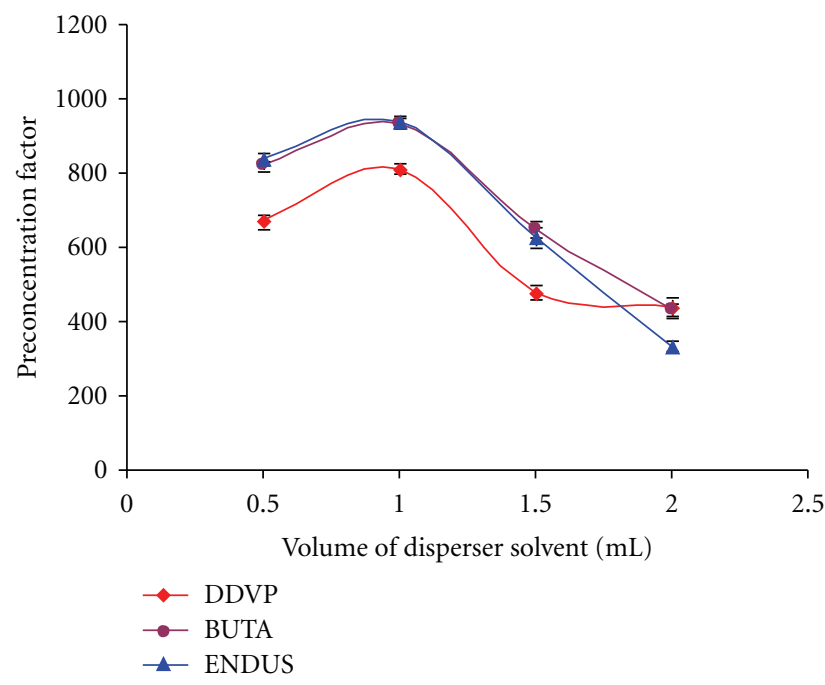

FIgure 5: The effect of disperser solvent (acetone) volume on the peak areas of analytes. Extraction conditions: water sample volume, $5.0 \mathrm{~mL}$; disperser solvent (acetone) volumes, 0.50, 1.0, 1.5, and $2.0 \mathrm{~mL}$; extraction solvent (1-undecanol) volumes, 9.0, 15.0, 25.0, and $30.0 \mu \mathrm{L}$; concentration of analytes, $100 \mu \mathrm{g} \mathrm{L}-1$.

of sedimented phase $(5 \pm 0.3 \mu \mathrm{L})$. As shown in Figure 5 , the peak areas of analytes were increased by increasing the volume of acetone from 0.5 to $1.0 \mathrm{~mL}$ and then decreased. It is probably due to the solubility increment of extraction solvent in water sample with increasing of acetone volume. Therefore, highest sensitivity was achieved when $1.0 \mathrm{~mL}$ acetone was used.

3.4. Effect of Salt. Sodium chloride was added into the sample solution to increase the ionic strength of the sample solution. The influence of amount of sodium chloride on the extraction efficiency was studied in the range of 
TABLE 1: Quantitative results of DLLME-SFO and GC-ECD of pesticides.

\begin{tabular}{|c|c|c|c|c|c|}
\hline Analyte & Linear range $\left(\mu \mathrm{g} \mathrm{L}^{-1}\right)$ & $\operatorname{LOD}^{\mathrm{a}}\left(\mu \mathrm{g} \mathrm{L}^{-1}\right)$ & R.S.D. $(\%)^{b}$ & $\mathrm{PF}^{\mathrm{c}}$ & $r^{\mathrm{d}}$ \\
\hline Endosulfan & $0.1-100$ & 0.05 & 3.2 & 905 & 0.9987 \\
\hline Butachlor & $0.05-100$ & 0.006 & 5.1 & 915 & 0.9954 \\
\hline Dichlorvos & $0.05-100$ & 0.008 & 6.7 & 802 & 0.9975 \\
\hline
\end{tabular}

${ }^{a}$ LOD: limit of detection for $S / N=3$.

${ }^{b}$ RSD: relative standard deviation $(n=5)$.

cPreconcentration factor at concentration of $10 \mu \mathrm{g} \mathrm{L}-1$.

${ }^{\mathrm{d}}$ Correlation coefficient.

TABle 2: Determination of endosulfan (EN), Butachlor (BU), and Dichlorvos (DI) in tap, sea, and river waters.

\begin{tabular}{|c|c|c|c|c|c|c|c|c|c|c|c|c|}
\hline \multirow{2}{*}{ Sample } & \multicolumn{3}{|c|}{ Concentration of analytes $\left(\mu \mathrm{g} \mathrm{L}^{-1}\right)$} & \multicolumn{3}{|c|}{ Added of analytes $\left(\mu \mathrm{g} \mathrm{L}^{-1}\right)$} & \multicolumn{3}{|c|}{ Found analytes $\left(\mu \mathrm{g} \mathrm{L}^{-1}\right) \pm \mathrm{RSD}, n=4$} & \multicolumn{3}{|c|}{ Relative recovery $(\%)$} \\
\hline & EN & $\mathrm{BU}$ & DI & $\mathrm{EN}$ & $\mathrm{BU}$ & DI & EN & BU & DI & EN & BU & DI \\
\hline Tap water ${ }^{\mathrm{a}}$ & n.d. ${ }^{\mathrm{d}}$ & n.d. ${ }^{\mathrm{d}}$ & n.d. ${ }^{\mathrm{d}}$ & 0.5 & 0.5 & 0.5 & $0.45 \pm 5.6$ & $0.48 \pm 3.2$ & $0.44 \pm 5.3$ & 90 & 96 & 88 \\
\hline Sea water ${ }^{b}$ & n.d. ${ }^{\mathrm{d}}$ & n.d. ${ }^{\mathrm{d}}$ & n.d. ${ }^{\mathrm{d}}$ & 0.5 & 0.5 & 0.5 & $0.43 \pm 6.7$ & $0.46 \pm 8.4$ & $0.45 \pm 4.5$ & 86 & 92 & 90 \\
\hline River water $^{\mathrm{c}}$ & n.d. ${ }^{\mathrm{d}}$ & n.d. ${ }^{\mathrm{d}}$ & n.d. ${ }^{\mathrm{d}}$ & 0.5 & 0.5 & 0.5 & $0.47 \pm 6.3$ & $0.49 \pm 7.1$ & $0.44 \pm 9.1$ & 94 & 98 & 88 \\
\hline
\end{tabular}

a From drinking water system of Tehran, Iran.

${ }^{\mathrm{b}}$ From Caspian sea (Sari, Iran).

'Syahrood river (Juybar, Iran).

d Not detected.

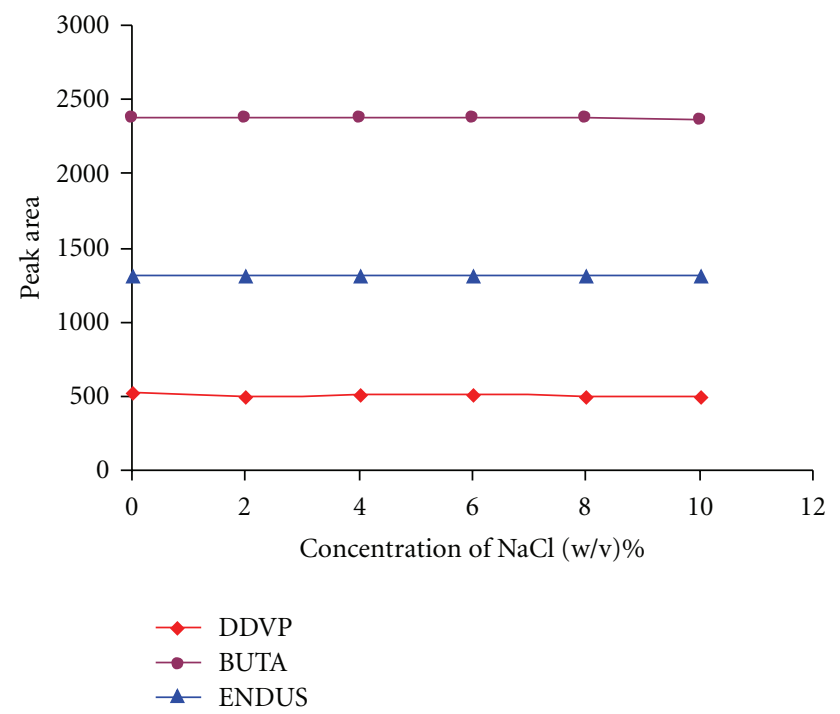

FIGURE 6: The effect of salt addition on the peak areas of analytes. Extraction conditions: water sample volume, $5.0 \mathrm{~mL}$; disperser solvent (acetone) volume, $1.0 \mathrm{~mL}$; extraction solvent (1-undecanol) volume, $15.0 \mu \mathrm{L}$; concentration of analytes, $100 \mu \mathrm{g} \mathrm{L}^{-1}$.

0 to $10 \%(\mathrm{w} / \mathrm{v})$. The experimental results show that the salt addition had no significant effect on the peak areas of pesticides and the extraction is quantitative (Figure 6). Therefore, further extractions were performed without any salt addition. The similar experimental results have been reported $[31,32]$.

3.5. Quantitative Aspects. The analytical performance of method was evaluated at optimized conditions. The linearity of the method was evaluated using water samples spiked with the selected compounds at twelve different concentration levels from 0.05 to $100 \mu \mathrm{g} \mathrm{L}^{-1}$. The precisions, limits of detection, and PF values results are listed in Table 1. The calibration curve for pesticides exhibited coefficient of determination $(r)$ ranging from 0.995 to 0.998 . The relative standard deviations (RSDs, $n=5$ ) based on the peak areas for five replicated runs were ranged from 3.2 to $6.7 \%$. The limits of detection (LOD) based on signal-tonoise 3 ranged from 0.05 to $0.008 \mu \mathrm{gL}^{-1}$ for most of the analytes. The PF values were calculated as the ratio of final concentration of analytes in the floated droplet to initial concentration of analytes in the aqueous solution. The results indicate that PF values are between 802 and 915. Table 3 comprises the performance data of the proposed method and other extraction methods. As shown in this table, the LOD values and linearities of the DLLME-SFO method were better than that of the many compared methods, especially for butachlor and Dichlorvos. Other validation data of the DLLME-SFO method were comparable to that of the other methods.

3.6. Environmental Real Samples Analysis. The study of probable matrix effects and applicability of the method in real sample analysis is investigated. The proposed method was used to determine the concentration levels of pesticides in three different water samples; sea, tap, and river waters. The sea, tap, and river water samples were filtered with Advantec number 2 filter paper. The analytical results of these samples indicated that sea, tap, and river water samples are free from target analytes. The concentration of analytes in the real samples was lower than the LOD of the proposed method. Therefore, the real samples were spiked with the studied compounds at concentration level of $0.5 \mu \mathrm{g} \mathrm{L}^{-1}$. Figure 7 shows GC-ECD chromatograms of the river samples 
TABLE 3: Comparison of performance data of DLLME-SFO method and other extraction methods with GC-ECD.

\begin{tabular}{|c|c|c|c|c|c|c|c|}
\hline Method & Analytes & $\operatorname{LOD}\left(\mu \mathrm{g} \mathrm{L}^{-1}\right)$ & R.S.D. (\%) & Linear range $\left(\mu \mathrm{g} \mathrm{L}^{-1}\right)$ & $r$ & Relative recovery $(\%)^{\mathrm{a}}$ & Ref. \\
\hline \multirow{3}{*}{ DLLME-SFO } & Endosulfan & 0.05 & 3.2 & $0.1-100$ & 0.998 & 94 & \multirow{3}{*}{ This work } \\
\hline & Butachlor & 0.006 & 5.1 & $0.05-100$ & 0.995 & 98 & \\
\hline & Dichlorvos & 0.008 & 6.7 & $0.05-100$ & 0.997 & 88 & \\
\hline \multirow{3}{*}{ SPME } & Endosulfan & 0.1 & 2.2 & $0.5-3$ & 0.998 & 99 & {$[33]$} \\
\hline & Butachlor & 0.01 & 1.44 & n.r. ${ }^{\mathrm{c}}$ & n.r. & - & {$[34]$} \\
\hline & Dichlorvos & 0.01 & 10.6 & $0.01-1.0$ & 0.994 & 117.3 & {$[32]$} \\
\hline \multirow{3}{*}{ DLLME $^{\mathrm{b}}$} & Endosulfan & 0.003 & 8 & $0.5-16$ & 0.999 & 100 & {$[35]$} \\
\hline & Butachlor & n.r. & n.r. & n.r. & n.r. & n.r. & - \\
\hline & Dichlorvos & n.r. & n.r. & n.r. & n.r. & n.r. & - \\
\hline \multirow{3}{*}{$\mathrm{SDME}^{\mathrm{d}}$} & Endosulfan & n.r. & n.r. & n.r. & n.r. & n.r. & - \\
\hline & Butachlor & 0.0006 & 9.4 & $0.05-50$ & 0.997 & 100 & {$[36]$} \\
\hline & Dichlorvos & 0.56 & 10.0 & $1.0-50$ & 0.999 & 98.6 & {$[37]$} \\
\hline \multirow{3}{*}{$\mathrm{SPE}^{\mathrm{e}}$} & Endosulfan & 0.02 & 6.4 & $0.05-1$ & 0.999 & 96 & {$[38]$} \\
\hline & Butachlor & n.r. & n.r. & n.r. & n.r. & n.r. & - \\
\hline & Dichlorvos & 0.2 & $4.0 / 3.5$ & $1-100 / 100-1000$ & $0.999 / 0.995$ & 78 & {$[38]$} \\
\hline
\end{tabular}

${ }^{\mathrm{a}}$ The relative recovery values are in the water real samples.

${ }^{\mathrm{b}}$ Dispersive liquid-liquid microextraction.

${ }^{\mathrm{c}}$ Not reported.

d Single drop microextraction.

esolid-phase extraction.

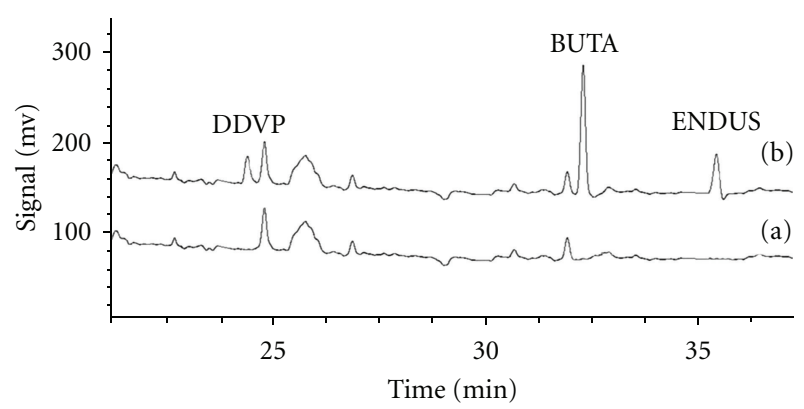

Figure 7: DLLME-SFO-GC-ECD chromatograms of the river sample under optimum conditions (a) before and (b) after spiking with $0.5 \mu \mathrm{g} \mathrm{L}{ }^{-1}$ of analytes.

(a) before and (b) after being spiked of the river water with analytes at $0.5 \mu \mathrm{g} \mathrm{L}^{-1}$ levels.

The relative recoveries were ranged from 86 to $98 \%$ for analytes as shown in Table 2 . The recoveries obtained for sea, tap, and river water samples were similar. These results demonstrated that DLLME-SFO is not significantly affected by the sample matrices. The recovery values of the proposed method were compared to that of other methods in Table 3, the results showed that the recovery values were in the range of recovery values of other reported method.

\section{Conclusion}

This proposed analytical method is simple, rapid, precise, and reproducible with wide linear range. Moreover, it used low toxic extraction solvent instead of high toxic solvent used in DLLME. However, the method does not require any additional specific equipment or training for extraction. In addition, it also outlined the successful application of the DLLME-SFO technique and allowed separation and preconcentration of pesticides at a low concentration level in the natural water samples.

\section{References}

[1] F. M. Liu, C. F. Qian, S. R. Jiang, and K. Hurle, "Observations of Pesticides in the Beijing Area (Air, Rain and Surface Water)," in Proceedings of the 18th Asian-Pacific Weed Science Society Conference, pp. 682-689, Beijing, China, May, 2001.

[2] Y. H. Ou, P. C. Chung, Y. C. Chang, F. Q. H. Ngo, K. Y. Hsu, and F. D. Chen, "Butachlor, a suspected carcinogen, alters growth and transformation characteristics of mouse liver cells," Chemical Research in Toxicology, vol. 13, no. 12, pp. 1321-1325, 2000.

[3] World Health Organization, Environmental Health Criteria for DDVP, Geneva, Switzerland, 1989.

[4] K. C. Barrons, A. J. Watson, and C. R. Worting, The Pesticide Manual, British Crop Protection Council, 7th edition, 1983.

[5] D. Xu, Z. Xu, S. Zhu et al., "Adsorption behavior of herbicide butachlor on typical soils in China and humic acids from the soil samples," Journal of Colloid and Interface Science, vol. 285, no. 1, pp. 27-32, 2005.

[6] J. J. Jiménez, J. L. Bernal, M. J. D. Nozal, and C. Alonso, "Liquid-liquid extraction followed by solid-phase extraction for the determination of lipophilic pesticides in beeswax by gas chromatography- electron-capture detection and matrixmatched calibration," Journal of Chromatography A, vol. 1048, no. 1, pp. 89-97, 2004.

[7] M. J. Redondo, M. J. Ruiz, R. Boluda, and G. Font, "Determination of pesticides in soil samples by solid phase extraction disks," Chromatographia, vol. 36, pp. 187-190, 1993. 
[8] C. L. Arthur, L. M. Killam, K. D. Buchholz, J. Pawliszyn, and J. R. Berg, "Automation and optimization of solid-phase microextraction," Analytical Chemistry, vol. 64, no. 17, pp. 1960-1966, 1992.

[9] H. Kataoka and J. Pawliszyn, "Development of in-tube solidphase microextraction/liquid chromatography/electrospray ionization mass spectrometry for the analysis of mutagenic heterocyclic amines," Chromatographia, vol. 50, no. 9-10, pp. 532-538, 1999.

[10] S.-F. Chen, Y.-S. Su, and J.-F. Jen, "Determination of aqueous chlorothalonil with solid-phase microextraction and gas chromatography," Journal of Chromatography A, vol. 896, no. 1-2, pp. 105-110, 2000.

[11] M. A. Farajzadeh and M. Hatami, "Solid-phase microextraction gas chromatography for determination of some organophosphorus pesticides," Chromatographia, vol. 59, no. 3-4, pp. 259-262, 2004.

[12] P. Helena and Z. K. Lucija, "Solid-phase microextraction," Trends in Analytical Chemistry, vol. 18, no. 4, pp. 272-282, 1999.

[13] M. A. Jeannot and F. F. Cantwell, "Solvent microextraction into a single drop," Analytical Chemistry, vol. 68, no. 13, pp. 2236-2240, 1996.

[14] L. Zhao and H. K. Lee, "Application of static liquid-phase microextraction to the analysis of organochlorine pesticides in water," Journal of Chromatography A, vol. 919, no. 2, pp. 381$388,2001$.

[15] M. Saraji and B. Farajmand, "Application of single-drop microextraction combined with in-microvial derivatization for determination of acidic herbicides in water samples by gas chromatography-mass spectrometry," Journal of Chromatography A, vol. 1178, no. 1-2, pp. 17-23, 2008.

[16] K.-J. Chia and S.-D. Huang, "Analysis of organochlorine pesticides in wine by solvent bar microextraction coupled with gas chromatography with tandem mass spectrometry detection," Rapid Communications in Mass Spectrometry, vol. 20, no. 2, pp. 118-124, 2005.

[17] M. B. Melwanki, S. D. Huang, and M. R. Fuh, "Threephase solvent bar microextraction and determination of trace amounts of clenbuterol in human urine by liquid chromatography and electrospray tandem mass spectrometry," Talanta, vol. 72, no. 2, pp. 373-377, 2007.

[18] P. Grossi, I. R. Olivares, D. R. de Freitas, and F. M. Lancas, "A novel HS-SBSE system coupled with gas chromatography and mass spectrometry for the analysis of organochlorine pesticides in water samples," Journal of Separation Science, vol. 31, no. 20, pp. 3630-3637, 2008.

[19] X. Yan, C. Yang, C. Ren, and D. Li, "Importance of extracting solvent vapor pressure in headspace liquid-phase microextraction," Journal of Chromatography A, vol. 1205, no. 1-2, pp. 182-185, 2008.

[20] A. Sarafraz-Yazdi, A. H. Amiri, and Z. Eshaghi, "BTEX determination in water matrices using HF-LPME with gas chromatography-flame ionization detector," Chemosphere, vol. 71, no. 4, pp. 671-676, 2008.

[21] S. Pedersen-Bjergaard and K. E. Rasmussen, "Liquid-liquidliquid microextraction for sample preparation of biological fluids prior to capillary electrophoresis," Analytical Chemistry, vol. 71, no. 14, pp. 2650-2656, 1999.

[22] L. Zhao, L. Zhu, and H. K. Lee, "Analysis of aromatic amines in water samples by liquid-liquid-liquid microextraction with hollow fibers and high-performance liquid chromatography," Journal of Chromatography A, vol. 963, no. 1-2, pp. 239-248, 2002.
[23] M. B. Melwanki, W. H. Hsu, and S. D. Huang, "Determination of clenbuterol in urine using headspace solid phase microextraction or liquid-liquid-liquid microextraction," Analytica Chimica Acta, vol. 552, no. 1-2, pp. 67-75, 2005.

[24] M. Rezaee, Y. Assadi, M. R. Milani Hosseini, E. Aghaee, F. Ahmadi, and S. Berijani, "Determination of organic compounds in water using dispersive liquid-liquid microextraction," Journal of Chromatography A, vol. 1116, no. 1-2, pp. 1-9, 2006.

[25] A. P. Birjandi, A. Bidari, F. Rezaei, M. R. M. Hosseini, and Y. Assadi, "Speciation of butyl and phenyltin compounds using dispersive liquid-liquid microextraction and gas chromatography-flame photometric detection," Journal of Chromatography A, vol. 1193, no. 1-2, pp. 19-25, 2008.

[26] J. Xiong and B. Hu, "Comparison of hollow fiber liquid phase microextraction and dispersive liquid-liquid microextraction for the determination of organosulfur pesticides in environmental and beverage samples by gas chromatography with flame photometric detection," Journal of Chromatography A, vol. 1193, no. 1-2, pp. 7-18, 2008.

[27] M. R. Khalili Zanjani, Y. Yamini, S. Shariati, and J. A. Jönsson, "A new liquid-phase microextraction method based on solidification of floating organic drop," Analytica Chimica Acta, vol. 585, no. 2, pp. 286-293, 2007.

[28] S. Dadfarnia, A. M. Salmanzadeh, and A. M. H. Shabani, "A novel separation/preconcentration system based on solidification of floating organic drop microextraction for determination of lead by graphite furnace atomic absorption spectrometry," Analytica Chimica Acta, vol. 623, no. 2, pp. 163-167, 2008.

[29] M. I. Leong and S. D. Huang, "Dispersive liquid-liquid microextraction method based on solidification of floating organic drop combined with gas chromatography with electron-capture or mass spectrometry detection," Journal of Chromatography A, vol. 1211, no. 1-2, pp. 8-12, 2008.

[30] H. Xu, Z. Ding, L. Lv, D. Song, and Y.-Q. Feng, "A novel dispersive liquid-liquid microextraction based on solidification of floating organic droplet method for determination of polycyclic aromatic hydrocarbons in aqueous samples," Analytica Chimica Acta, vol. 636, no. 1, pp. 28-33, 2009.

[31] P. Liang, J. Xu, and Q. Li, "Application of dispersive liquidliquid microextraction and high-performance liquid chromatography for the determination of three phthalate esters in water samples," Analytica Chimica Acta, vol. 609, no. 1, pp. 53 $58,2008$.

[32] C. Gonçalves and M. F. Alpendurada, "Multiresidue method for the simultaneous determination of four groups of pesticides in ground and drinking waters, using solid-phase microextraction-gas chromatography with electron-capture and thermionic specific detection," Journal of Chromatography A, vol. 968, no. 1-2, pp. 177-190, 2002.

[33] J. L. Raposo-Junior and N. Re-Poppi, "Determination of organochlorine pesticides in ground water samples using solid-phase microextraction by gas chromatography-electron capture detection," Talanta, vol. 72, no. 5, pp. 1833-1841, 2007.

[34] E. C. Zhao, W. L. Shan, S. R. Jiang, Y. Liu, and Z. Q. Zhou, "Determination of the chloroacetanilide herbicides in waters using single-drop microextraction and gas chromatography," Microchemical Journal, vol. 83, no. 2, pp. 105-110, 2006.

[35] C. Cortada, L. Vidal, R. Pastor, N. Santiago, and A. Canals, "Determination of organochlorine pesticides in water samples by dispersive liquid-liquid microextraction coupled to gas 
chromatography-mass spectrometry," Analytica Chimica Acta, vol. 649, no. 2, pp. 218-221, 2009.

[36] E. C. Zhao, W. L. Shan, S. R. Jiang, Y. Liu, and Z. Q. Zhou, "Determination of the chloroacetanilide herbicides in waters using single-drop microextraction and gas chromatography," Microchemical Journal, vol. 83, no. 2, pp. 105-110, 2006.

[37] Q. Xiao, B. Hu, C. Yu, L. Xia, and Z. Jiang, "Optimization of a single-drop microextraction procedure for the determination of organophosphorus pesticides in water and fruit juice with gas chromatography-flame photometric detection," Talanta, vol. 69, no. 4, pp. 848-855, 2006.

[38] M. C. Pablos-Espada, F. J. Arrebola-Liébanas, A. GarridoFrenich, and J. L. Martínez-Vidal, "Analysis of pesticides in water samples using GC-ECD and GC-MS/MS techniques," International Journal of Environmental Analytical Chemistry, vol. 75, no. 1-2, pp. 165-179, 1999. 


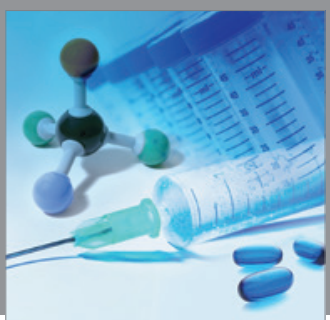

International Journal of

Medicinal Chemistry

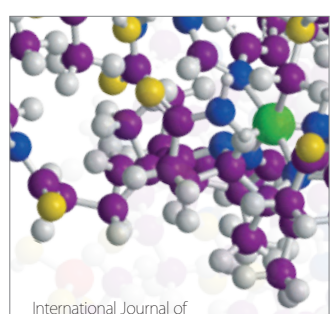

Carbohydrate Chemistry

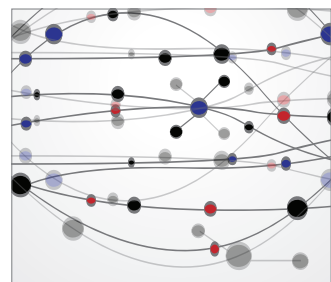

The Scientific World Journal
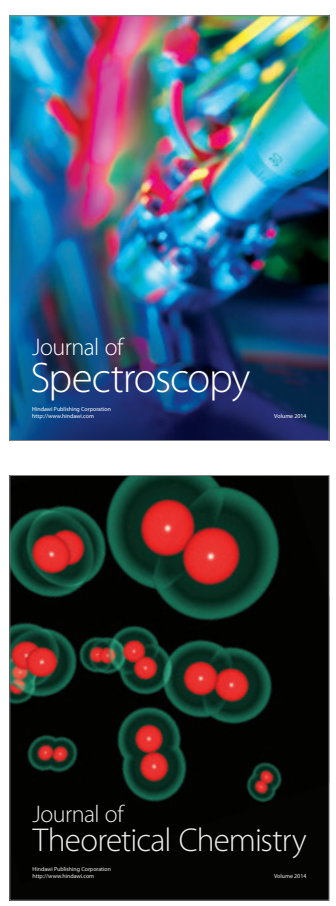
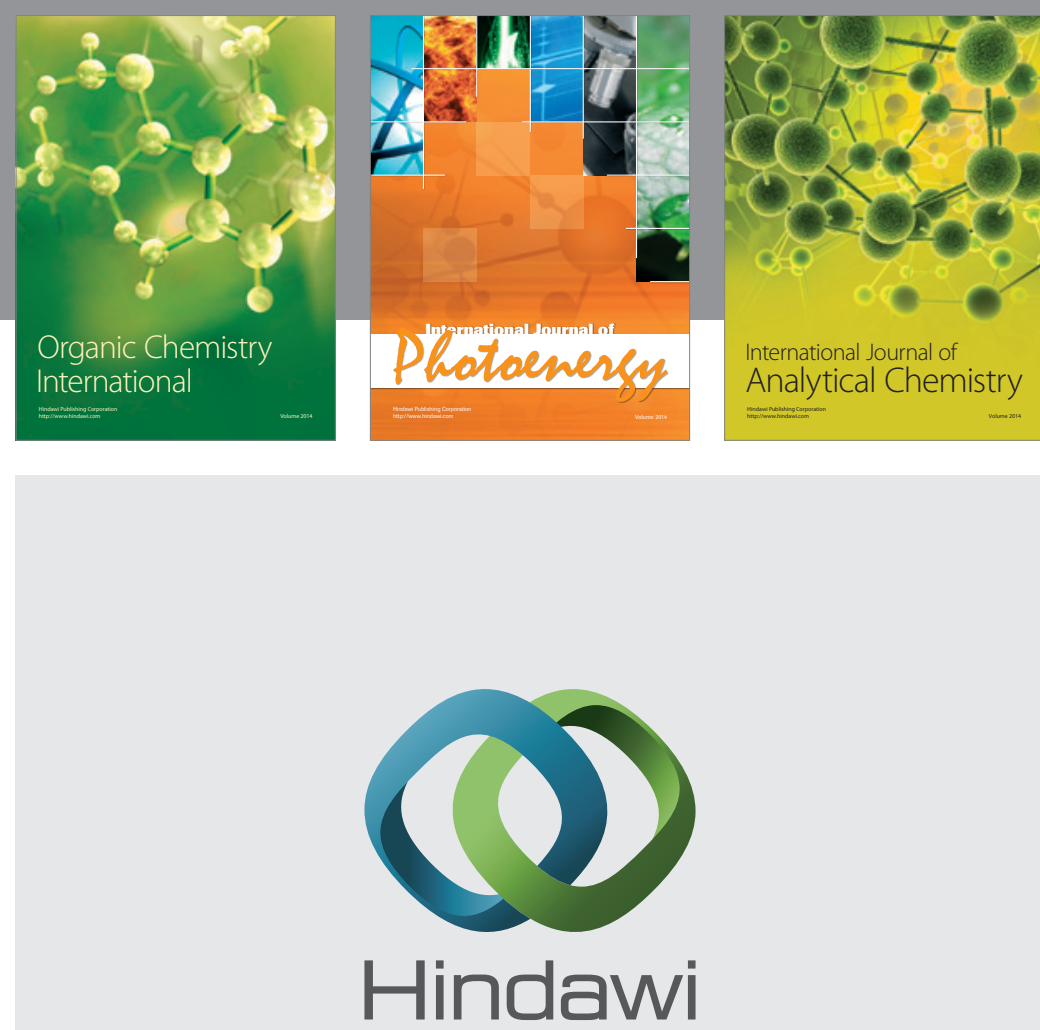

Submit your manuscripts at

http://www.hindawi.com
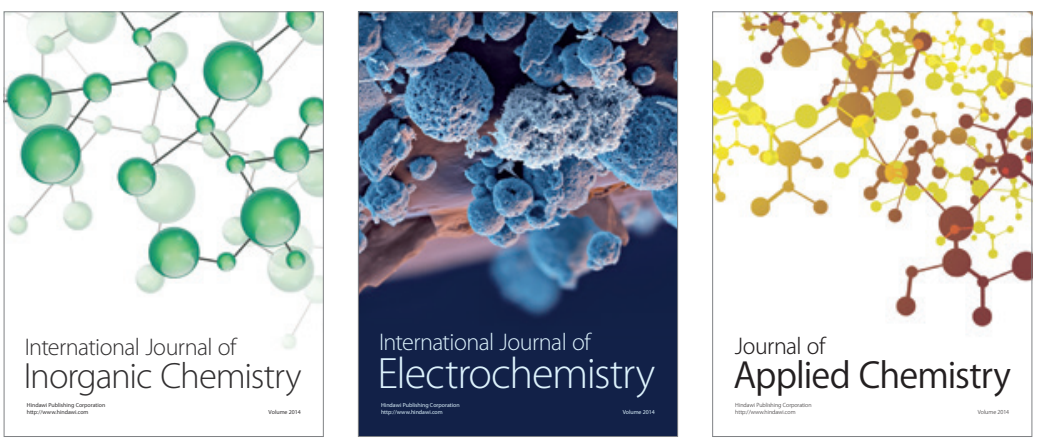

Journal of

Applied Chemistry
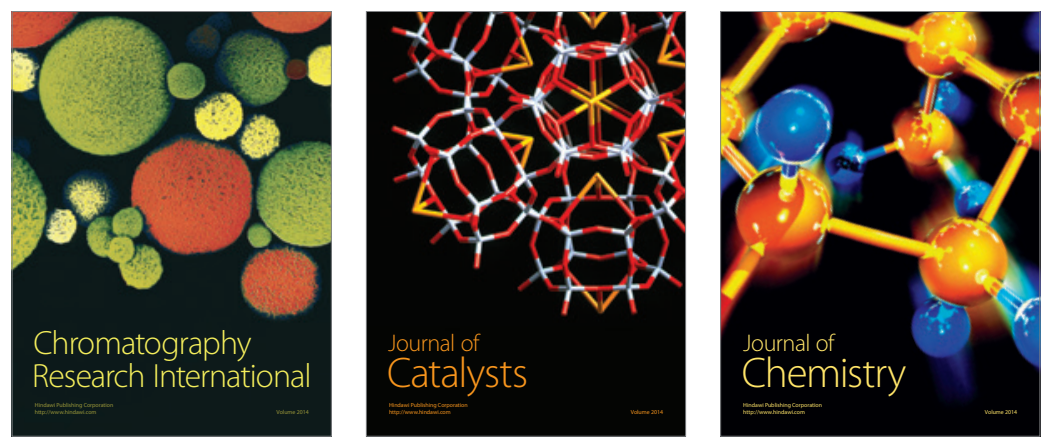
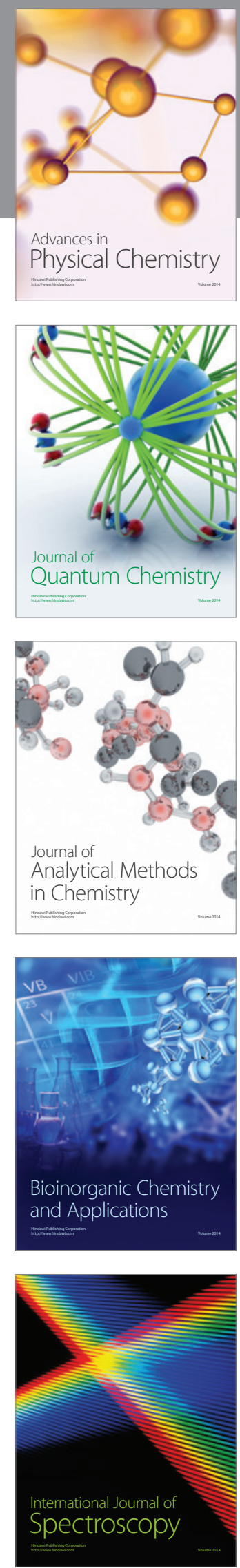